\title{
Photovoltaic Manufacturing Technology, Phase 1, Final Report
}

\section{Final Subcontract Report 9 January 1991 - 14 April 1991}

J. H. Wohlgemuth, D. Whitehouse, S. Wiedeman, A. W. Catalano, R. Oswald Solarex Corporation

Frederick, Maryland

NREL technical monitor: R. Mitchell

National Renewable Energy Laboratory

(formerly the Solar Energy Research Institute) 1617 Cole Boulevard

Golden, Colorado 80401-3393

A Division of Midwest Research Institute Operated for the U.S. Department of Energy under Contract No. DE-AC02-83CH10093

Prepared under Subcontract No. XC-1-10057-3

December 1991 


\section{On September 16, 1991, the Solar Energy Research Institute was designated a national laboratory, and its name was changed to the National Renewable Energy Laboratory.}

This publication was reproduced from the best available camera-ready copy submitted by the subcontractor and received no editorial review at NREL.

\section{NOTICE}

This report was prepared as an account of work sponsored by an agency of the United States government. Neither the United States government nor any agency thereof, nor any of their employees, makes any warranty, express or implied, or assumes any legal liability or responsibility for the accuracy, completeness or usefulness of any information, apparatus, product, or process disclosed, or represents that its use would not infringe privately owned rights. Reference herein to any specific commercial product, process, or service by trade name, trademark, manufacturer, or otherwise does not necessarily constitute or imply its endorsement, recommendation, or favoring by the United States government or any agency thereof. The views and opinions of authors expressed herein do not necessarily state or reflect those of the United States government or any agency thereof.

\section{Printed in the United States of America \\ Available from: \\ National Technical Information Service \\ U.S. Department of Commerce \\ 5285 Port Royal Road \\ Springtield, VA 22161}

Price: Microfiche A01

Printed Copy A03

Codes are used for pricing all publications. The code is determined by the number of pages in the publication. Information pertaining to the pricing codes can be found in the current issue of the following publications which are generally available in most libraries: Energy Research Abstracts (ERA); Government Reports Announcements and Index (GRA and I); Scientific and Technical Abstract Reports (STAR); and publication NTIS-PR-360 available from NTIS at the above address. 


\section{DISCLAIMER}

Portions of this document may be illegible electronic image products. Images are produced from the best available original document. 


\section{INTRODUCTION AND SUMMARY}

Solarex Corporation was founded in 1973 as the first commercial company specializing in terrestrial photovoltaics. Solarex was purchased by Amoco Corporation in 1983. With the support of Amoco, Solarex has remained an active participant in the commercial production of photovoltaic modules. Solarex is involved in all commercial aspects of PV, including manufacture, sales, market development, applications development, systems development, reliability testing, process and equipment development (particularly automation) and research and development of new processes, materials and products.

Solarex has made PV commitments to both Crystalline Silicon and Thin Film Silicon technologies. Solarex believes that these two distinctly different technologies, each with it's own market segments, will coexist for the foreseeable future. Therefore, Solarex has continued to support both technologies, maintaining active R\&D programs as well as funding increases in manufacturing capacity for both divisions. This contract covered both crystalline silicon and amorphous silicon technologies.

In the first phase of the manufacturing initiative, the steps which must be taken to achieve low cost, large area PV modules from a large volume manufacturing process were. identified. Cost reductions associated with each step were estimated and compared to the present manufacturing costs for processes now used at the Crystalline and Thin Film Divisions. At Solarex the actual costs of producing PV modules are well known, since Solarex commercially produces both crystalline silicon and amorphous silicon PV products. However, rates for overhead and G\&A may not scale with volume or technology change. To address the need for accurate projections of PV selling prices, a cost model was applied to the manufacturing processes now used at Solarex.

The cost model, IPEG2, was a simplification of the SAMICS methodology developed by JPL for DOE1,2. The SAMICS costing program originated from detailed analysis of a facility designed for commercial PV module fabrication. The factors which determine production cost are appropriately divided among such categories as production equipment, direct labor, direct materials, physical floor space and utilities. Overhead rates to cover indirect costs and allow for adequate return on investment 
were determined by JPL based on a large number of SAMICS computer runs.

$\begin{array}{lr}\text { Material Overhead } & 20 \% \\ \text { Utilities Overhead } & 20 \% \\ \text { Fringe Benefits } & 30 \% \\ \text { Overhead on Labor + Fringe } & 110 \%\end{array}$

JPL also provided a yearly equipment cost based on the projected equipment lifetime, for example $57 \%$ for a 7 year life, and a yearly floor space cost that when adjusted for inflation equaled $\$ 169 /$ square foot per year. The use of this JPL model allows us to compare and quantify the cost advantages obtained by envisioned changes in the manufacturing process.

The description of this work is structured into four sections, each describing the program effort in a particular task, with each section broken down into a subsection for crystalline silicon and a subsection for amorphous silicon.

In Task 1 a detailed description of the 2 process sequences in use today was prepared. The costs associated with each of these steps were calculated using actual materials usage, labor, product yields, etc. These data were used as inputs into the JPL cost model to estimate the selling price at which these PV modules should be available for sale. The technologies now in use and the calculated selling prices for these technologies form a basis for comparison for the envisioned technology improvements.

In Task 2 a number of potential routes to lower cost were compared via the JPL cost model. The results were specific proposed process sequences that result in considerable cost savings. In the Crystalline case the calculated selling price can be reduced by more than a factor of 2 using a process sequence quite similar to the one now in production. Proposed changes in the sequence include:

- Advanced Casting System

- Wire Saw Wafering

- Automated Cell Line with Transparent Conductive Oxide Coating

- Lower Cost Backsheet

- Frameless Mounting Designs 
The proposed Thin Film technology utilizes a triple junction a-Si:H based process. When applied to large areas and high volumes, the calculated selling price is reduced by $85 \%$ from the baseline technology now in production. Triple junction technology improves both the cell efficiency and the long term stability providing a more desirable final product.

In Task 3 specific areas were identified that would be the most difficult technical achievements required to implement the process sequence listed in Task 2. Some of these are specific to the particular technology under study like wire saws for crystalline silicon or implementation of triple junction technology for amorphous $\mathrm{Si}$. Others are generic and apply to almost all PV technologies. Generic problems include the issue of framing/mounting and automated handling of large numbers of cells/modules.

In Task 4 preliminary research plans were developed to solve the technical problems identified in Task 3 . The programs required to solve these problems are described. It is important to note that in most cases the technologies proposed have been demonstrated in the laboratory already. The major efforts in manufacturing scale-up involve engineering for larger sizes, greater volumes and for cost effectiveness. In both cases analyzed, crystalline silicon and thin film, Solarex believes that the prospects for successfully solving these problems and implementing production of the low cost technologies described in Task 2 are excellent. 


\section{TASK 1 CURRENT SOLAREX TECHNOLOGY}

\section{CRYSTALLINE TECHNOLOGY}

Solarex's Crystalline Silicon Technology is based on use of cast polycrystalline silicon wafers. The process flow is shown in Table 1. The primary product is a module with 36 solar cells $(11.4 \mathrm{~cm} . \times 11.4 \mathrm{~cm}$.) that produces 60 Watts under Standard Test Conditions (STC). Solarex's module manufacturing process can be divided into six sub-processes. These are (i) feedstock, (ii) casting, (iii) wafering, (iv) cell fabrication, (v) lamination and (vi) finishing. Each of the process steps is described below.

\section{(i) Feedstock}

Casting allows Solarex to use off-grade silicon feedstock, rather than depending on more expensive semiconductor grade silicon. During casting of silicon or other silicon bulk crystal growth processes like Czochralski $(\mathrm{CZ})$, the large segregation coefficient of most carrier lifetime killers results in reduction of impurity concentrations in the solid. Impurities are rejected into the melt during growth and end up in the last material that freezes. Also in casting, since the ingot solidifies from bottom to top, the growth front is under the liquid surface. Surface oxides and impurities trapped in these oxides remain on the surface and are not incorporated in the growing solid. This is in contrast to $\mathrm{CZ}$ crystal growth where the crystal grows from the melt surface, requiring an extremely clean liquid-solid-gas interface. Solarex is, therefore, able to use offgrade polycrystalline silicon as well as being able to use $C Z$ tops and tails as feedstock for the casting process. These materials are available on a continuing basis. A certain percentage of the polycrystalline silicon feedstock produced falls into these off-grade categories and can not' be sold to the semiconductor industry. Likewise, every time a single crystal is grown, a certain amount of tops and tails material is generated as scrap to the semiconductor industry. Since this material is not usable by the semiconductor industry, it is available at reduced prices.

\section{(ii) Casting}

Solarex has developed and patented a directional solidification casting 
process specifically designed for photovoltaics. In this process, polycrystalline silicon feedstock is melted in a ceramic crucible and solidified into a large grained semicrystalline silicon ingot. In house manufacture of low cost, high purity ceramics is a key to the low cost fabrication of Solarex semicrystalline wafers. 3,4

The casting process is performed in Solarex designed casting stations. The casting operation is computer controlled. There are no moving parts (except for the loading and unloading) so the growth process proceeds with virtually no operator intervention.

There is little cost reduction to be made in this area by further automation or change in materials and equipment. The most important improvement in this area would address improving material quality to increase cell efficiency.

\section{(iii) Wafering}

Wafering is done with Internal Diameter (ID) saws. These are the same saws that are used in the semiconductor industry to wafer single crystal $\mathrm{CZ}$ ingots. At present ID saws are the lowest variable cost wafering option. Solarex has many years of experience with these saws, resulting in low labor and process costs. In addition, many of the saws are already fully depreciated. This is a mature technology with little opportunity for significant increases in productivity or reduction in kerf loss.

\section{(iv) Cell Process}

The cell process sequence is based on the use of Thick Film Paste (TFP) metallization, where a commercially available screen printed silver paste is applied as the current carrying grid on the front of the solar cell. This process has been designed to be as cost effective as possible. The high temperature process steps including diffusion, firing of the front print paste and Chemical Vapor Deposition (CVD) of the antireflective (AR) coating are all performed in belt furnaces. Cells are automatically unloaded from cassettes onto the belts and automatically reloaded into cassettes at the end of the belts. At present cassettes are still manually transported between processes and through the wet process steps. 
Although a number of the process steps on the cell line are well known in the industry, two of the steps have been developed and patented by Solarex and are unique to Solarex's cell line. One of these is the technology used to deposit the dopant on the front of the wafer. This dopant/diffusion process is low cost, does not require use of toxic gases and provides a continuous flow of wafers on belts through the doper and the diffusion furnace.

The second of these unique process steps is the sprayed back contact. The entire back side of the wafer is sprayed with aluminum. Then stripes of a solderable metal are sprayed where the back tabs are to be soldered. This back metallization system is not only the lowest cost system, but also provides the back contact with (a) minimal contact resistance, (b) good bulk conductivity for back collection through the aluminum and (c) ease of soldering to the back with high pull strengths.

Polycrystalline cells processed through this line have an average cell efficiency of 12.5 to $13 \%$ at STC. There are many modifications to this process sequence that will increase cell efficiencies. However, most of these modifications actually increase the total dollar per watt module cost rather than decrease it. Detailed cost analyses indicate what changes in cell processing can lead to both higher cell efficiencies and lower dollar per watt module cost.5 Implementation of these changes require laboratory verification of the candidate process sequences as well as improvement in the accuracy of the input cost data.

\section{(v) Module Lamination}

The first part of the module fabrication sequence is to solder two solder plated copper tabs onto the front of the solar cells. Each tab is soldered in 4 places for reliability and redundancy. Solarex uses automated machines to perform the tabbing.

Tabbed cells are then laid up into a 36 cell matrix by a robot. The tabs are then soldered to the backs of the solar cells by another robot. Each tab has 2 back solder joints. The assembled matrices are then checked for voltage continuity on a light table.

The module construction consists of a low iron, tempered glass 
superstrate, EVA encapsulant and a 3 part Polyethylene-Mylar-Tedlar backsheet. The lamination process, including the cure, is performed in a vacuum lamination system. Then the modules are trimmed and the leads are attached. Finally, every module is flash tested to determine it's STC power output.

Any proposed changes to module materials or construction techniques must not reduce the module lifetime or reliability. The glass-EVA-Tedlar system has proven extremely reliable with a very low failure rate.

Solarex modules of this type have now been in the field for nearly 10 years, with minimal failures and no measurable degradation of output power.6 Solarex now warranties these modules for 10 years and expects them to have a lifetime in excess of 20 years. Such lifetimes and reliability are necessary to make PV economic, so that only cost reductions that do not effect module reliability and lifetime should be considered.

\section{(vi) Finishing}

At present most modules are sold with a frame to protect the edges and provide a means of mounting. Solarex uses an extruded aluminum frame that is attached both with a butyl rubber adhesive between frame and glass as well as with 2 screws in each corner of the frame. The entire framing process is performed by a fully automatic, robotic framing system. This one system meets all of Solarex's framing capacity requirements.

Most modules are sold with a junction box to protect the output wiring and provide the terminals for electrically connecting the module to the balance of the system. The area where the lead wires are attached to the module is potted with RTV to protect the laminate from moisture incursion. The junction box is then attached to the module with adhesive to seal it to the back of the laminate and with a screw to hold it to the frame. The module lead wires are soldered to the output terminals and the J-box lid is attached. The modules get a final cleaning and inspection just before being boxed for shipment to the customer.

Since most of the labor has already been taken out of the framing cost, direct materials (frame \& J-box) comprise most of the direct cost of framing. While cost reductions in frame design are possible, large 
reductions in framing cost require development of module mounting systems that do not require any frame on the module, but rather directly attach a laminate onto the support structure.

In summary, recent Solarex cost reductions have been achieved by applying automation to manufacturing (especially wafer and cell handling) and by incremental improvements in known processes to increase yield, improve cell efficiency and reduce operating costs. Continued increases in volume and automation of the production line will reduce the costs below today's value. However to produce Crystalline PV at levels competitive with other (non-PV) energy forms will require modifications to the process to reduce cost and increase efficiency. 


\section{TABLE 1 \\ 1991 SOLAREX CRYSTALLINE PROCESS SEQUENCE}

\section{PROCESS}

Silicon Feedstock

Casting

Wafering

Cell Line

$\mathrm{NaOH}$ Etch

Diffusion

Edge Isolation

HF Etch

Screen Print

Front Fire

AR Coating

Back Spray

Cell Test

Lamination

Cell Tab

Cell Matrix

Lamination

Trim \& Wire

Test

\section{Finish}

Frame \& J-Box

Box \& Ship

\section{EQUIPMENT}

Purchased

Casting Stations

ID Saws

Tanks

Belt Doper and Furnace

Plasma Etch

Tanks

Printers

Belt Furnace

Belt CVD Furnace

Spray with Belt Feed

Xenon Lamp

Glass-EVA-Tedlar

Auto with Solder Plated Copper

Auto

Laminator

Flash Xenon

Framing Robot 


\section{THIN FILM TECHNOLOGY}

The Solarex Thin Film Division was founded in 1983 to develop and commercialize thin film a-Si:H based technology for the photovoltaic power generation market. This technology offered promise of high conversion efficiency and very low cost. Since 1983 steady improvements in the a-Si:H technology at Solarex have led to pilot plant production and sale of PV consumer products for low power applications. The progress made since the inception of the Solarex Thin Film Division can be divided into two major areas: advances in module conversion efficiency through research and advances in manufacturing technology through process and equipment development.

World record efficiencies for both single junction and multi-junction large area $(1000 \mathrm{~cm} 2)$ modules have resulted from research on a-Si:H based materials and devices at Solarex Thin Film Division. This research, which has been supported by DOE and SERI, has driven the evolution from low efficiency, single junction a-Si:H modules to large area, triple junction modules of 9 to $10 \%$ conversion efficiency. 7 Moreover, the triple junction technology has decreased the light induced degradation in high efficiency a-Si:H based cells from greater than $50 \%$ to only about $10 \%$ after one year of field exposure. These efficiency measurements have been confirmed by SERI. These advances in triple junction technology, which are responsible for increased performance, have not yet been incorporated into the present manufacturing process, which is still based on thin, single junction modules of $5 \%$ conversion efficiency. Thus, it is expected that the transfer of the triple junction technology from research to manufacturing will reduce the price per watt of a-Si:H based modules by approximately a factor of two.

Extensive automation of a-Si:H based solar cell manufacture has also been under development at Solarex Thin Film Division. Many of the problems posed by manufacture of large area, low cost PV have been solved through the design and construction of three generations of specialized PV manufacturing equipment. The first generation of equipment was semiautomated and as such resulted in higher labor costs. It is still in use today. The second generation of equipment comprises a more highly automated, computer integrated manufacturing line (CIM) for small a-Si:H single junction modules. The CIM line is based on the concept of "glass in, 
product out". The CIM process virtually eliminates the requirements for operator handling from all of the thin film material deposition steps to achieve lower cost and improved quality. The importance of minimizing cost through automation is evident; the cost of direct labor represents nearly one third of the total cost of an unframed PV module produced on the semi-automated, first generation equipment. The labor cost has been reduced by one half through the utilization of a greater level of automation in the second generation CIM line. The greatest cost reduction of the CIM line is realized as a result of increased speed of processing into complete modules and better yield due to the reduced requirement for handling. This second generation manufacturing line is under final engineering test. It will soon be dedicated to full production of a-Si:H single junction product.

The third generation of Solarex a-Si:H based PV manufacturing equipment is designed to achieve further economies of scale. Much higher production rates are planned based on the experience and advances gained by development of the first two generations of a-Si:H manufacturing equipment. This latest generation of $\mathrm{PV}$ manufacturing equipment now under development at Solarex Thin Film Division utilizes more extensive computer integration and control than the second generation CIM line. It is also designed to manufacture much larger power system modules. Automation and computer control will be used to greatly reduce the manual labor currently required for encapsulation, wiring, test, framing and packaging. Throughput in this third generation of equipment will also be increased by these improvements and by scale up of those processes that are rate-limiting in the earlier generation systems. The third generation equipment is now under engineering development.

The process steps used in the present single junction a-Si:H manufacturing process at Solarex are shown in Table 2. The process involves the successive deposition and subsequent laser scribing of the three thin film components on a transparent substrate. Ordinary sodalime window glass is used as the substrate because of its low cost, availability and suitability for this application. The three thin film components which constitute the solar cell are a transparent, electrically conductive front contact of textured tin oxide, the semiconductor layers of amorphous silicon (a-Si:H) and amorphous silicon carbide (a-SiC:H) and a rear metallic contact of aluminum. Each component and the associated processing steps are described below. 


\section{(i) Transparent Front Contact}

The transparent front contact consists of electrically conductive tin oxide (CTO) deposited using tin tetrachloride feedstock over a thin layer of silicon dioxide $\left(\mathrm{SiO}_{2}\right)$, which acts as a barrier to diffusion of impurities from the soda-lime glass. Small amounts of proprietary dopants and chemicals are added to the reaction during tin oxide deposition to increase the electrical conductivity and provide physical texture. A textured layer is required to increase solar cell efficiency via optical scattering of light in the cell. Both the silicon dioxide $\left(\mathrm{SiO}_{2}\right)$ and the tin oxide $\left(\mathrm{SnO}_{2}\right)$ layers are deposited in a belt furnace at atmospheric pressure.

\section{(ii) Laser Patterning Process}

Most applications of $\mathrm{PV}$ modules require voltages that are greater than the nominal voltage output of a single a-Si:H junction. A thin film module can be made to deliver the desired voltage by dividing the PV module into segments which are then electrically connected in series. This process involves cutting each layer (CTO, a-Si:H, metal) individually via laser scribing or patterning to create series connected PV segments. The process relies on laser scribing of a-Si:H and subsequent metal deposition through this opening to form the interconnections between segments. An effective process for selectively cutting each of the layers has been developed at Solarex using frequency-doubled Nd:YAG laser technology. By proper adjustment of the laser parameters the finely focussed laser beam can be made to ablate either the thin film semiconductor layers, the transparent СTO layer or all layers including the rear metal contact. The present laser scribing process is computer controlled using machine vision and linear motion. Multiple beam cutting is incorporated into this step to increase throughput.

\section{(iii) Semiconductor Deposition Process}

The thin film a-Si:H semiconductor and its related alloys are deposited in load lock vacuum chambers of Solarex design using DC plasma decomposition of silane and methane. The semiconductor in the current process actually consists of three sublayers, denoted " $p$ " or " $n$ " for the 2 doped layers and " $\mathrm{in}$ for the intrinsic or undoped layer. The doped layers are formed by adding small amounts of boron or phosphorous containing 
compounds to the feed gases during the plasma deposition. The single junction process starts with the deposition of the $p$ type (boron doped) a-SiC:H layer on top of the CTO front contact, followed by deposition of the intrinsic layer and finally the $n$ type (phosphorous doped) layer. The total thickness of all the semiconductor layers is about 0.30 microns. Process variables such as temperature, pressure plasma current, and gas flow rates are all carefully controlled in the deposition chamber.

\section{(iv) Back Contact Metal Deposition}

The rear contact is formed by sputter deposition of aluminum performed after deposition and laser scribing of the CTO and semiconductor layers. Magnetron sputtering equipment was specially designed by Solarex to achieve high deposition rates and to minimize the cost of this process step. Subsequent to the metal deposition a final laser scribe is performed near the perimeter of the module to isolate the active area from edge defects.

\section{(v) Test and Encapsulation}

The completed solar modules are tested in a large area solar simulator for proper electrical output under illumination. The encapsulation system used for the first generation process is an acrylic film applied over the aluminum ribbon contacts. The aluminum ribbon is ultrasonically bonded to the back contact of the module and has pads to which wire leads are soldered. A silicone based adhesive is applied around the solder joints to prevent corrosion or failure due to exposure to the environment. The wires are attached to the module by means of standard soldering.

The second generation system eliminates much of the manual labor described above through the use of low temperature fired contact pads which are applied to the module before deposition of the semiconductor layers. This process is amenable to automation. The second generation system uses an automated system to spray encapsulate the modules.

The process described does not include the operation to mount the solar module in a frame. The module is completely functional in a stand alone fashion, without a frame, however a frame is requested by many end users for appearance and ease of mounting. In our cost analyses the framing costs have been considered separately to allow clear comparison of the 
effects of process improvements on the functional product. It is interesting to note that the cost of the thin film modules has been reduced to the point that the cost of the frame dominates all other material costs. It is anticipated that in many cases mounting requirements for thin film modules based on this large area, glass/thin film technology will be satisfied by integration of the module support structure into the existing structural element (i.e. field array, roof, greenhouse, etc.). 


\section{TABLE 2 1991 SOLAREX THIN FILM PROCESS SEQUENCE}

PROCESS

Glass Substrate

Seam and Wash Glass

Deposition of Textured CTO and Frit

Laser Scribing of CTO and Wash

Deposition of a-Si:H

Single Junction PIN Cell

Laser Scribing of a-Si:H

Deposition of Aluminum

Back Contact

Laser Scribing of Back Contact and Wash

Test

Encapsulate

Finish

Wiring

Frame

Box \& Ship

\section{EQUIPMENT}

Purchased

Belt System

Atmospheric CVD Belt Furnace

Machine vision/location, $X-Y$ Beam Translation and

Frequency Doubled Nd:YAG Lasers

DC Plasma Deposition System

Machine vision/location, $X-Y$ Beam Translation and Frequency Doubled Nd:YAG Lasers

Magnetron Sputtering Equipment

Machine vision/location, $X-Y$ Beam Translation and

Frequency Doubled Nd:YAG Lasers

Solar Simulator

Spray Encapsulation

Lead Bonding Equipment

Tooling 


\section{TASK 2 ENVISIONED SOLAREX TECHNOLOGY .}

\section{CRYSTALLINE TECHNOLOGY}

The technology envisioned to reduce cost is based on the continued use of cast polycrystalline silicon wafers. The process flow is shown in Table 3. The cost analysis was based on the manufacture of modules with $36-16$ to $17 \%$ efficient solar cells $(11.4 \mathrm{~cm} . \times 11.4 \mathrm{~cm}$.). Cost reductions will be achieved by (i) higher cell efficiencies through improvements in casting and modifications to the cell process, (ii) more efficient use of materials because of thinner wafers and increased process yields, (iii) reduction in the labor content via automation and (iv) reduction in materials costs, particularly the elimination of frames. The IPEG cost analysis indicated that this process sequence would result in module selling prices less than one-half that of the baseline presented in Task 1. The envisioned improvements in the six sub-processes are described below.

\section{(i) Feedstock}

During this time period, Solarex expects the volume of shipped Megawatts to increase significantly. However, because of projected increases in cell efficiency and the use of thinner wafers from the wire saw, the increase in silicon feedstock will not be nearly as large. Reducing the amount of silicon required per Megawatt is important because the off-grade silicon supply is limited. Only by limiting the increased demand will the price for the feedstock remain at the same level as now.

\section{(ii) Casting}

Solarex has been developing an Advanced Casting Station to improve material quality. Improved control of crystal growth produces a more uniform ingot, resulting in higher yields. Reduction of the stresses during crystal growth and cool-down improves the overall material quality resulting in higher efficiency cells without changing the overall cost of an ingot.

\section{(iii) Wafering}

Wire saws have the advantage of cutting thinner wafers with less kerf 
loss, i.e., producing more wafers for the same amount of silicon. In addition, for the same capital equipment investment, a wire saw will produce a much larger number of wafers than a similar investment spent on ID saws. Therefore, the least costly way to expand capacity involves adding additional wafering capacity with wire saws, while continuing to operate the ID saws already in place.

\section{(iv) Cell Process}

One of the most important improvements required to reduce cost is to increase the cell conversion efficiency. This efficiency improvement will require both casting developments that result in better material and modifications to the cell process sequence to further raise the efficiency, while retaining low-cost cell processing.

\section{(v) Module Lamination}

There are no proposed changes to the encapsulation materials because of the reliability requirements. The lamination cost goals will be achieved by full automation and by bulk purchase of the lamination materials. Reductions in the backsheet cost are possible by using 2 or even 1 part materials.

\section{(vi) Finishing}

The key to reducing the finishing cost is to develop frameless system designs so that most modules are sold without frames. In most systems the structural support provided by the frame is duplicated by the support structure. Therefore, frames can be eliminated, significantly reducing the finishing cost. 


\section{TABLE 3 \\ ENVISIONED 1995 SOLAREX PROCESS SEQUENCE}

\section{PROCESS}

Silicon Feedstock

Casting

Wafering

Cell Line

$\mathrm{NaOH}$ Etch

Diffusion

Edge Isolation

TCO

Screen Print

Front Fire

Dual AR Coating

Back Spray

Cell Test
EQUIPMENT

Purchased

Advanced Casting Station

Wire Saws + ID Saws

Automated System

Belt Doper + Furnace

Plasma Etch

CVD Furnace

Auto-Printers

Belt Furnace

Belt CVD Furnace

Auto Spray

Auto with Xenon Lamp

Lamination

Glass-EVA-Tedilar

Fully Automated Tab, Matrix, Lay-up, Lamination, Trim, Wire \& Test

Finish

Termination

Box \& Ship
Auto

Auto 


\section{THIN FILM TECHNOLOGY}

Since PV product is evaluated in terms of cost/watt, those factors that minimize cost and maximize power output are paramount. Therefore, stabilized conversion efficiency is of utmost importance. Significant improvements in stabilized efficiency of large area a-Si:H based solar modules have been recently made at Solarex. These improvements, demonstrated under DOE supported research programs at Solarex, derive mostly from the development of triple junction technology, improved rear reflecting contacts and compressed laser scribes.

Triple junction a-Si:H based technology offers several important advantages including better utilization of the solar spectrum, a reduced rate of light-induced degradation and reduced power loss in the CTO top conductive contact. Amorphous silicon with a typical band gap of $1.72 \mathrm{eV}$, does not absorb much light at wavelengths longer than about $720 \mathrm{~nm}$. Triple junction cells, however, have a narrow band gap a-SiGe:H alloy junction at the rear, that absorbs the additional energy in the solar spectrum available from 720 to $860 \mathrm{~nm}$. The first two junctions of the triple junction are typically made of a-Si:H, but are substantially thinner than would be required to achieve a similar efficiency for only a single junction cell. The reduced thickness of the first two a-Si:H junctions lead to the second advantage of the triple junction cell. Because the a-Si:H intrinsic layer is thinner, the electric field in those layers is substantially higher. The increased electric field, particularly in the top cell, reduces the light induced degradation due to the Staebler-Wronski effect.8 The second and third cells also suffer less light induced degradation because the intensity of light incident on these cells is reduced because of optical absorption in the first cell. Lastly, some additional resistance to light induced degradation is gained in the bottom cell through the use of germane, which has been shown to increase stability in the amorphous silicon based alloys.9

Prior to the advent of triple junction technology, the ramifications of light induced degradation (Staebler-Wronski effect) were severe. Indeed, the cell design for single junction a-Si:H based commercial product is dictated by the need to minimize this degradation. A thick (8000A), high efficiency (12\%), a-Si:H single junction cell would, at best, stabilize after one year at $40 \%$ of its initial efficiency. 8 It is for this very reason that 
at present single junction a-Si:H products use a thin (2600 $\AA$ ) intrinsic amorphous silicon layer. Although these thin single junction modules are less efficient initially (typically less than $6 \%$ ), they are more resistant to light induced degradation, retaining at least $75 \%$ of their initial efficiency. Triple junction technology, however, makes use of both the stability inherent in thin individual silicon layers and the efficiency improvements available by using three separate junctions for better utilization of the energy in the solar spectrum. Measurements made on triple junction a-Si:H/a-Si:H/a-SiGe:H cells show 9 to $10 \%$ initial efficiencies which retain 80 to $90 \%$ of their performance after the first year of use.7 Hence, the stabilized performance of a-Si:H based modules can be increased by more than $80 \%$ with triple junction devices.

The largest gain in cost per watt for manufactured a-Si:H based PV modules can be achieved by transferring the triple junction technology to larger area modules. The proposed process sequence is shown in Table 4. The IPEG cost analysis indicates that just the change from the single junction small area module to the triple junction large area module would yield a module selling price that is reduced by $78 \%$ from the baseline process now in use and described in Task 1.

Other changes envisioned in the technology include

- Better gas utilization through electrode/gas distribution design.

- Use of lower cost metallization, the substitution of zinc oxide for indium tin oxide for the rear contact.

- Gas recycling.

- Better cell design, improvements in semiconductor quality, front and rear contacts.

These additional changes can lead to a $10 \%$ stabilized triple junction module at a projected module selling price that is approximately $15 \%$ of today's profitable selling price.

One of the striking results of the cost model is that a tremendous reduction in cost/watt of PV product occurs when the production volume is scaled to about 10 Megawatts per year. This cost advantage results because the capital cost of equipment, the labor costs and the materials costs scale sub-linearly with production rate. The scaling process is very 
significant for a continuous process that can be adapted to handle larger substrates. The thin film, amorphous silicon technology developed at Solarex is particularly well suited for scale-up, because it is a continuous rather than a batch process and all steps involve processing or transport in a planar geometry. None of these planar processing steps (plasma deposition, laser scribing, etc.) place a physical constraint on substrate size. Moreover, the a-Si:H process is a relatively low temperature process which allows for rapid heating and cooling. Thus scale-up should be accomplished very effectively via rapid processing of much larger substrates. 


\section{TABLE 4 1995 SOLAREX THIN FILM PROCESS SEQUENCE}

PROCESS

Glass Substrate

Seam and Wash Glass

Deposition of Textured CTO and Frit

Laser Scribing of CTO and Wash

Deposition of a-Si:H

First PIN Cell

Deposition of a-Si:H

Second PIN Cell

Deposition of a-SiGe:H

Third PIN Cell

Deposition of Zinc Oxide

Back Contact

Laser Scribing of Back Contact and $\mathrm{a}-\mathrm{Si}$ and Wash

Test

Encapsulate

Wiring

Box \& Ship
EQUIPMENT

Purchased

Belt System

Atmospheric CVD Belt Furnace

Machine vision/location, $X-Y$ Beam Translation and

Frequency Doubled Nd:YAG Lasers

DC Plasma Deposition System

DC Plasma Deposition System

DC Plasma Deposition System

Atmospheric CVD Belt Furnace

Machine vision/location, $X-Y$ Beam Translation and Frequency Doubled Nd:YAG Lasers

Solar Simulator

Spray Encapsulation

Lead Bonding Equipment 


\section{TASK 3 EXPECTED PROBLEMS}

\section{CRYSTALLINE TECHNOLOGY}

Substantially reducing the crystalline silicon module cost requires changes in the process sequence as well as continued automation to meet the expanding market. The six sub-processes must be evaluated as part of an integrated process sequence to understand the interactions between changes in one area and the subsequent impacts to the rest of the line. The expected problems, that may be encountered during implementation of the proposed low cost process sequence presented in Task 2, are described below for the six sub-processes. A final subsection will summarize those problems considered generic to the crystalline PV industry.

\section{(i) Feedstock}

Solarex would prefer not to have to develop a manufacturing technology to produce low cost silicon feedstock in the next 5 years (although this may eventually become a necessity as crystalline silicon PV grows). In this 5 year time frame the plans are to continue to rely on utilizing available offgrade silicon feedstock material. Improvements in cell conversion efficiency and material usage will limit the increase in feedstock requirements.

Improvements in cast material quality make it possible to intentionally dope the bulk silicon to achieve a lower bulk resistivity, resulting in higher cell voltages and conversion efficiencies. A further benefit of this change is the ability to use an expanded resistivity range of tops and tails as feedstock.

\section{(ii) Casting}

Casting efforts are required in two areas, (a) improvements in casting technology to improve material quality leading to increased yield and higher cell efficiency and (b) reduction of the bulk resistivity to take better advantage of cell process improvements. These two areas are discussed below.

(a) Solarex has developed a laboratory version of an Advanced Casting 
Station (ACS). This unit was designed as a research tool to explore improvements in the casting process. Experimental results indicate that the ACS process can produce cast silicon ingots that make cells with efficiencies nearly equal to those obtained on $C Z$ silicon. The best cells from the ACS already have this efficiency.

(b) Theoretically a solar cell with lower base resistivity will have higher conversion efficiency due to higher open circuit voltage, all other cell parameters being the same. However, as the silicon is more heavily doped with boron to lower the resistivity, the minority carrier lifetime decreases resulting in a reduction in current collection. The selection of the optimum base resistivity depends on the trade-off between increasing voltage and decreasing current. The better the quality of the grown silicon the less it exhibits reduction in minority carrier lifetime for an equivalent doping level. Before 1985 Solarex cast polycrystalline silicon had an optimum cell conversion efficiency at a bulk resistivity of $1.5 \mathrm{ohm}-$ $\mathrm{cm}$. Below this resistivity the minority carrier lifetime decreased rapidly resulting in lower cell efficiencies.

In 1987 Solarex switched to the use of high purity ceramic crucibles, significantly reducing the impurity content of the silicon ingots. At the same time the dopant level of boron was increased to reduce the bulk resistivity to $0.7 \mathrm{ohm}-\mathrm{cm}$. This change resulted in an increase in cell open circuit voltage, a small decrease in short circuit current and a $2 \%$ increase in average cell output power. 3 With today's casting technology further reductions in bulk resistivity lead to a reduction of the cell efficiency, but the improvements in casting from the ACS program result in a reduction of structural defects and improved minority carrier lifetime. This material should be more tolerant of higher doping levels, so a reduction in bulk resistivity is expected to improve cell efficiency, particularly when coupled with some of the higher efficiency cell processes discussed in the cell subsection.

\section{(iii) Wafering}

Solarex has been experimenting with wire saws since 1986. In 1988 four Shaping Systems wire saws were transferred to production and operated as production units. The wire saws have demonstrated that they can produce $20 \%$ more wafers per ingot than the ID saws, at equivalent yields, with equivalent surface quality and at a much higher throughput rate per 
capital expenditure. This experience, however, also has uncovered three problems that must be solved before wire saws can fully replace ID saws.

(a) These wire saws themselves were not durable enough for manufacturing. The continued mechanical motion of the saw and the carry-out of cutting slurry results in extreme wear of the saw. The down time and cost of maintenance for these saws added appreciably to the cost of cutting a wafer.

(b) The cost of consumables (wire, oil, grit, etc.) is too high. Significant progress has been made in reduction of consumable costs. Improvements in slurry, slurry feed and machine control of tension has allowed us to increase the number of cuts per wire and to double the number of cuts per batch of slurry. Further improvements will require a better understanding of the actual cutting process including why the slurry stops cutting as well, how to get the slurry into the cut area more effectively and how to increase the cut rate of silicon and not of the wire.

(c) Removal of the wafers after cutting remains a problem. At present after the adhesive releases the wafers, they must be manually removed from the solvent and cassetted. This can result in unacceptable high breakage and labor cost. This will become even more important when handling thinner wafers.

\section{(iv) Cell Process}

Changes in the cell process must increase efficiency without increasing the module cost. Cell efficiencies greater than $17 \%$ have been reported on Solarex cast silicon.11 Solarex has analyzed many of these processes and has identified a number of process sequences that have the potential to reach $16.5 \%$ cell efficiency cost effectively. 5

The 12.5 to $13 \%$ average efficiency of today's production cells is limited by both the material and the process. Material developments were discussed in the casting subsection above. In addition, the projected reduction in bulk resistivity will make the proposed cell process changes more effective in raising efficiency.

The main limitation on efficiency from the cell process is the interaction of the cell metallization with the cell emitter. In today's cells, to make 
adequate ohmic contact, the $\mathrm{Ag}$ paste requires the emitter to be doped to a sheet resistance of 40 to $60 \mathrm{ohms} / \mathrm{square}$. This doping level is much too heavy for optimum cell efficiency. A number of process options are possible to alleviate this problem. The major issue is identifying and implementing a process that is cost effective.

\section{(v) Module Lamination}

Cost improvements in lamination are based on automation, that is already underway, volume purchase of materials and reduction in the cost of the back sheet. Reliability and lifetime considerations restrict the options in this area. Many different materials can be used as backsheet, but the critical issue is finding a lower cost material that retains the same level of reliability, especially to wet high-pot failure.

\section{(vi) Finishing}

Efforts are already underway to develop module mounting schemes that do not require frames. Solarex's PVUSA EMT-1 array is an example of this approach. Such designs must meet all of the environmental requirements, such as wind and snow loading as well as reducing the necessary field assembly labor. A number of engineering designs are likely to meet these requirements. An industry wide study of mounting schemes could assist the entire PV industry.

\section{(vii) Generic Issues - Crystalline Silicon}

An important generic issue for crystalline silicon PV manufacturers is the ability to handle and process thinner wafers, since the use of thinner wafers can significantly reduce the silicon required per watt and lead to lower cost. A major question is how to handle these thin wafers through the manufacturing line. At present Solarex processes 300 micron thick wafers. Experiments with processing of thinner, 250 micron thick, wire saw wafers, resulted in higher breakage in the cell and module lines. Handling equipment designed for 300 micron thick wafers can easily suck holes right through the thinner wafers. Since the use of thinner wafers will help the entire crystalline silicon PV industry, a engineering effort to understand how to handle such wafers and development of loading and unloading equipment would be of great value. 


\section{THIN FILM TECHNOLOGY}

The plan to reduce the amorphous silicon module cost requires implementation of triple junction technology and scale-up to both large area and large volume. The expected problem areas are discussed below. A final section will summarize those problems considered generic to the thin film PV industry.

\section{(i) Scale-up and Automation}

The problems which may be encountered in scale-up and implementation of highly automated, large volume production of large area, cost effective a-Si:H based modules represents a diverse set of hurdles, but with no insurmountable barriers. One challenge is posed by the outright speed at which large area PV modules must be processed at every step in the manufacturing line. Simple calculations show that continuous processing of substrates two feet in width must take place at a linear rate greater than 120 feet per hour in order to produce 10 Megawatts per year in a three shift operation. The implications of this challenge have become apparent through the past experience in PV production at Solarex Thin Film Division. The first two generations of a-Si:H PV manufacturing equipment at Solarex Thin Film represent very significant steps along a learning curve leading to the high volume, cost effective manufacturing capability required to achieve success. In some sense this problem is generic to the entire PV industry. That is, any PV technology will also require a very high processing rate at each and every manufacturing step in order to produce PV at the volumes expected in the near future (greater than 10 Megawatts per year). The difficulties in reaching the required processing speed is greatly reduced by using a technology like thin film amorphous silicon, which is not limited to small processing widths or small substrate areas, which is not based on batch processing and does not require high temperature processing.

\section{(ii) Yield Loss}

An important factor impacting the cost of thin film PV product is the yield loss of modules due to the formation of undesirable shunt paths. Early experience with the fabrication of large area, triple junction modules in a research environment indicates that shunting at point defects inevitably occurs, but represents a problem which varies widely 
depending on the size of the shunt. Many of the shunts are small and can be electrically "cured" by passing a large current pulse through them, presumably burning them out. This is not always an entirely satisfactory solution, because some shunts can not be cured by this means and because some shunts spontaneously redevelop after curing.

A second factor that affects yield loss in the process is due to glass breakage. Past experience has usually turned up a link between thermal nonuniformity, mechanical failure or unsatisfactory handling of the module and breakage of the glass substrate. Substrate breakage often causes unscheduled equipment downtime in addition to loss of product.

A third factor that could potentially reduce yield for larger modules, is the yield loss due to nonuniform laser scribes. This is anticipated because the laser beam which patterns the thin film layers of the module must be finely focussed to function properly. The focus can be maintained only at a specific distance between the focal lens and the module surface. Variations in depth or z-axis spacing can thus be responsible for the loss of laser focus, and consequently, poor or incomplete laser scribes.

Although this problem is not serious on the present small substrates, the greater scribe length required for larger modules could represent a much more serious problem. This problem is exacerbated in the multi-beam scribing needed for high throughput when beam-to-beam alignment must be carefully maintained.

\section{(iii) Materials Usage and Cost}

Cost constraints must be considered when moving from the research laboratory to a manufacturing environment. Two significant materials costs associated with the modules produced in the research laboratory may be undesirable or prohibitive in a large volume manufactured product. These two materials are the germane feed gas used for the third cell of the triple junction cell and the indium-tin-oxide/silver (ITO/Ag) highly reflective rear contact. The germane gas is considerably more expensive than the silane used for the other two cells. Similarly, the indium-tinoxide and silver are more expensive than the aluminum now used for back contacts for the single junction modules in production today. Fortunately, thin film technology requires only small amounts of these material. There is also the potential to use less expensive materials as substitutes. 


\section{(iv) Transfer of Triple Junction Technology to Manufacturing}

While triple junction technology has been demonstrated in the laboratory, the transfer to a manufacturing environment will require a significant engineering effort. Achieving the projected efficiency, stability, yield, throughput and material usage goals will be required to reduce the production cost to the level projected for triple junction modules.

\section{(v) Framing}

The present frames used on amorphous silicon consumer modules are as much cosmetic as functional. If properly encapsulated, a-Si:H modules do not require frames. Efforts therefore must be made to design mounting schemes that do not require the modules to be framed, but that still meet all of the environmental requirements such as wind and snow loading as well as module specific requirements like edge seals. An industry wide study of mounting schemes could assist the entire PV industry.

\section{(vi) Encapsulation and Accelerated Testing}

One problem facing PV technology is the requirement for stable electrical output from the product. In the case of a-Si:H based technology, this involves both the intrinsic stability of the semiconductor and the extrinsic stability related to corrosion and other environmental effects. The triple junction technology, utilizing a number of thinner silicon layers, has much reduced the adverse effect of the intrinsic light induced degradation in the a-Si:H. Corrosion and other environmental effects are still of great concern, however, although significant progress has been . made at Solarex to solve this problem. Fortunately, the requirements for the encapsulant, that protects the PV module, are much less severe for PV technologies such as Solarex's amorphous silicon technology where the active PV device is deposited directly onto a transparent glass substrate. onto which the light is incident. In this case the encapsulant must only protect the back (non-light incident) side of the module.

There is presently a great need for an accepted accelerated environmental test procedure for thin film modules. Testing time must be as brief as possible, but must reliably indicate the expected performance from actual exposure to the outdoor environment for the projected life of the module. Such a test sequence is needed in order to test a variety of potential 
encapsulation systems for development of highly reliable, low cost encapsulation systems for thin film PV modules.

\section{- (vii) Generic Issues - Thin Film}

Generic issues for thin film PV technology include:

- $\quad$ Automated handling of large area pieces of glass.

- Development of an accelerated environmental test sequence.

- Development of stable thin film devices.

- Development of reliable, low cost encapsulation systems.

These were each discussed above in the relevant subsections.

\section{GENERIC ISSUES - ALL PV TECHNOLOGIES}

The major generic issue affecting all flat plate PV technologies is the high cost of module frames. The cost analysis indicated that framing cost is a significant component of cost today, being approximately $35 \%$ of the cost of a small a-Si:H consumer module and approximately $10 \%$ of the cost of a crystalline silicon power module. If modules will continue to be framed, this component of cost will become an increasingly larger fraction of the total cost, until it represents about $50 \%$ of the cost of an a-Si:H triple junction power module or nearly $20 \%$ for a crystalline silicon power module in 1995.

The technical question involves designing support structures on which unframed modules can be directly mounted. Design of such systems hardware will be applicable to most PV technologies. 


\section{TASK 4 PROGRAMS TO SOLVE PROBLEMS}

To solve the potential problems identified in Task 3 as obstacles to implementing the process sequence identified in Task 2, a set of programs that include both Research and Development as well as Engineering Development are required.

\section{CRYSTALLINE TECHNOLOGY}

In crystalline silicon technology six specific development programs have been identified, namely (i) advanced casting, (ii) wire saw, (iii) high efficiency cell process, (iv) lower cost backsheet, (v) frameless modules and (vi) handling of thinner wafers. Each is discussed below.

\section{(i) Advanced Casting}

Solarex has an on-going program in casting to improve the uniformity and overall quality of the cast polycrystalline silicon. This effort includes experimental work with the Advanced Casting Station (ACS) and modelling work utilizing a finite element analysis program to model both the crystal growth and subsequent cooldown of the ingot. Optimum crystal growth will be directional with only slight curvature of the growth front, reasonably uniform and slowly nucleated. Stress analysis modelling of the cooldown indicates that the least stress requires minimum radial gradients and uniform linear vertical gradients. Optimization of the furnace geometry continues to produce more uniform, higher quality silicon.

The quality of the cast silicon depends on the levels of both structural and impurity defects. The use of high purity feedstock and purification via the segregation coefficient means that Solarex cast polycrystalline silicon has low concentrations of most lifetime killers. 3 Recent studies, however, indicate that the difference in cell efficiencies between $F Z$ and CZ silicon may be due to oxygen and possibly carbon levels in the $C Z$ material.12 Since today's cast poly has similar levels to $C Z$, the levels of carbon and oxygen may be an important high efficiency issue.

With continued improvement in the casting process, cell performance is 
expected to approach that of $\mathrm{CZ}$ silicon at much lower manufacturing cost.

\section{(ii) Wire Saws}

Solarex's experience with the Shaping Systems prototype wire saws revealed many critical machine problems that may be corrected in the current models of wire saws. The main improvements have been to wire guides, pulleys and wire handling. The shafts and pulleys of the original saws were plagued by design flaws that required frequent rebuilds with new bearings and seals, adding significant cost related to parts, labor and downtime. Present designs of wireguides and pulleys should last up to 8 times longer between servicing and require less service time due to modular design. Therefore the first step in the wire saw program would be the purchase of one of these new, improved wire saws.

With the prototype saws the wire speed was limited to a practical maximum of 2.5 meters/second. Improvements to the wire handling system have resulted in the ability to use much higher wire speeds. Machine manufacturer's tests with wire speeds up to 10 meters/second have shown that cutting speed increases 5.5 times as wire speed increases from 2.5 to 10 meters/second.13 This allows each wire saw to have a much higher throughput capacity, thereby reducing spending on capital equipment.

During the development of the wire saw process at Solarex, consumable utilization was improved by a factor of two. However, it still remained at a much higher level than experienced for ID saws. Further optimization of these materials can drive costs down with a combination of material cost, utilization and throughput improvements. Different wire tempers and alloys need further test to determine the strongest, longest wearing and most fault free wire. Factors to study include: wear rates, tensile strength of the worn wire, inclusions and kinking.

Process optimization of the wire saw is primarily empirically driven through the methodical variation of materials and equipment parameters with on line and off line measurements and characterization of physical and operational parameters used to control and evaluate the process. The increased cutting rates reported above are not well understood. Theories are based on the arguments that the cutting rate may be related to the kinetic energy of the grit or to grit shape and size distribution and its 
interaction with the oil viscosity and wetting properties. Sedigraph and SEM analysis is utilized to classify and specify the grit. Viscosity and composition are specified for the oils. The cutting mechanism is not understood well enough for total process specification. Optimization studies must be done on the wire saws themselves. For example, theory suggests that higher wire speeds may work better with lower viscosity oils, but what really matters is the viscosity of the working slurry actually in the cut itself. This viscosity is calculated from machine parameters and can be used in combination with baseline measurements in material selection. Process optimization will involve varying slurry constituents and monitoring the cutting process. Yields, usage rates, material cost and throughput will be used to judge the cost effectiveness of the process. Trends in measured characteristics of the process and materials have to be correlated with this estimate of cost and used to direct the experimentation.

Wafer demounting, cassetting and cleaning are presently done manually by the saw operator while the saws are running, but not in need of attention. Successful operation requires loosening of the wafers from the beam and removal of the slurry from between the wafers in solvent before they can be cassetted and rinsed. Variations in slurry age, solvent cleanliness and operator skill affect the yield of this process. Automation of this process is necessary to eliminate the need for operator skill and judgement, to free the operators to run more product on the saws themselves and finally to reduce the operator's exposure to cleaning solvent. Development is needed on improved fixturing, improved solvent delivery systems, automatic demounting and automatic wet stack to cassette equipment.

Disposal of the waste slurry has become an increasingly larger cost component as environmental regulations become more stringent. Waste slurry consists of oil, silicon carbide, silicon and iron. The oil is the greatest environmental liability, but also the most recoverable part of the slurry. Investigations of the potential to economically segregate the oil from the grit are required. Use of water soluble slurries has been reported, but since these are usually glycol based, they have similar environmental problems. The selection of the most economic slurry system will probably be driven by how well it functions in the cutting process rather than by costs of recovery and disposal, although these costs must be included in the final decision. 


\section{(iii) High Efficiency Cell Development}

While there are many routes to high efficiency solar cells, the goal of this effort is to select the most cost effective design for large scale manufacture. Solarex has done a significant amount of analysis and development in this area.5 A number of promising modifications to the present baseline cell process were identified in this reference, including:

- Use of a Transparent Conductive Oxide (TCO) between the emitter and the metallization.

- Improved optical coupling by texturing or double layer AR coating.

- Gettering to improve bulk lifetime, for example by phosphorous treatment before emitter formation.

- Surface passivation to reduce surface recombination velocity. The front surface will become more important as the bulk resistivity is reduced and as the emitter is more lightly doped. The back surface recombination velocity will become more important as the wafers become thinner and the bulk minority carrier diffusion length increases.

Each of these processes requires laboratory verification of the performance. Then an integrated process sequence has to be developed and proven in pilot production with verification of the cost assumptions before transfer to manufacturing.

\section{Low Cost Backsheet}

The first step in developing a new low cost backsheet material is to identify what the requirements are for the backsheet material. In Solarex's crystalline silicon module the backsheet provides the following functions:

- $\quad$ Serves as a mechanical barrier.

- Serves as an electrical barrier, particularly wet high-pot.

- Adheres well to the EVA encapsulant. 
- The back side must be easily bonded to for attachment of the J-Box, sealing of output leads and possibly attachment to the mounting structure.

- The backsheet must be compatible with the module passing the UL flame test.

The backsheet must be capable of meeting these requirements, but be low cost. A good target cost is $\$ 0.10 /$ square foot.

Solarex has selected ethylene based polymers as the starting point for this effort. Interactions with vendors of such films will be required to identify candidate materials and to obtain samples. Processing tests should include the ability to be laminated in the present process, ability to adhere to the EVA and identification and testing of adhesives for attachment to the back of the module. Samples must then be put through accelerated environmental tests as well as being deployed outdoors.

\section{Frameless Modules}

A number of concepts have been proposed for mounting of modules without frames. Actual deployed systems include the clips used on the Solarex PV USA emerging technology array and a number of Arco Solar systems where the modules are glued directly to the support structure. Both of these concepts and any other proposed frameless mounting schemes should be analyzed on the basis of cost and to determine their ability to withstand the expected mechanical loads, such as wind or snow.

Systems that are acceptable in terms of loading and cost should be tested both at outdoor test sites and via accelerated testing, including typical PV environmental tests (Block V, CEC 503, UL) as well as tests specifically designed to evaluate the mounting concept such as wind tunnel tests or array level wet high-pot tests.

Concepts that successfully pass the cost, design and accelerated test criteria, should be evaluated in demonstration arrays at well controlled and documented test facilities.

\section{Handling Thinner Wafers}

There is a great deal of silicon wafer handling equipment available for 
both the PV and semiconductor industries. Much of this equipment is designed for round, relatively thick wafers. There is also equipment available for handling square ceramic substrates. While very little of this equipment can be used as is for thinner square wafers of polycrystalline silicon, some of it can be modified to handle this material. The key issue is with what kind of yield this equipment can operate.

The preliminary effort in this area should entail a survey of the various methods utilized to move and handle wafers. Evaluation of various approaches such as suction cup pick-up, Bernoulli feed, use of rails or Orings should be undertaken for large area thin wafers.

The process itself should be reviewed in terms of handling. For example, can wafers be stacked and unstacked automatically with high yields, or should stacks be avoided. Likewise, are loading and unloading of cassettes high yield process steps or should wet steps be performed via other techniques. Once a few reliable methods for handling and moving large thin wafers have been identified, actual process equipment can be engineered by and built for the specific PV companies. 


\section{THIN FILM TECHNOLOGY}

\section{(i) Scale-up and Automation}

The use of equipment which is capable of manufacturing larger size PV modules at a faster rate is the most effective way to reduce the direct labor content of the cost. One of the advantages of thin film a-Si:H based technology is that it is amenable to full automation and scale-up because a single large area substrate is involved, rather than many small components which all require handling and assembling. Moreover, there are a limited number of processing steps required which involve only low temperature, planar processing with brief heating and cooling times. Even with these inherent advantages, the requirements imposed by the overall processing speed that is necessary to turn almost 6,000 square feet of glass per day into finished PV modules, are significant. The requirement for processing speed will be met by 1) use of equipment that is capable of processing large area substrates, 2) the use of multiple, sequential plasma deposition chambers, 3 ) operation of the CVD furnace for CTO deposition at a higher rate, 4) the use of automated (robotic) equipment to load, handle and unload, 5) the design and use of special equipment to automate the "back-end" processing and testing of modules and 6) the use of a multiple beam, vertical laser scribing system.

Improving the equipment used for the manufacture of a-Si:H based PV modules to handle larger substrate sizes is mainly a matter of scaling up the basic equipment used in the present process (CVD belt furnace, plasma CVD chamber and sputtering chambers). Some subtleties exist, such as increased substrate "sag" because of the larger size glass. This can be circumvented by processing the substrate vertically during the a-Si:H deposition and laser scribing steps. The crucial factors are the proper design of the plasma deposition chambers, which are required to deposit good quality, uniform films of a-Si:H, alloys of a-SiC: $\mathrm{H}$ and alloys of a-SiGe:H onto a large area vertical substrate. Fortunately, many of the issues involved in such a deposition have already been solved at Solarex for smaller substrates in the second generation CIM line. This experience has shown that temperature uniformity during the processing is an important consideration. Uneven heat transfer has been implicated as one of the major causes of glass breakage during film deposition. The design of the larger chambers will incorporate design improvements to avoid such thermal problems. 
The rapid processing speed not only requires quick, uniform heating of very large substrates, but also multiple, sequential plasma deposition chambers. For the triple junction design, the thickest layers in the cell, such as the second and third intrinsic layers, require longer deposition times than for the completion of other process steps. To prevent these steps from limiting the process rate for the entire line, multiple deposition chamber, in series, are planned for growth of the thickest layers in several steps.

Solarex Thin Film Division has a vast amount of experience with the CVD growth of high quality, textured tin oxide for the top, transparent conductive contact. Additional improvements are planned, including better control of the larger atmospheric CVD belt furnace, elimination of microscopic debris formation during the tin oxide step and increased furnace throughput. Some of the anticipated improvements are modifications to the injector head, implementation of liquid metering pumps, better regulation of differential furnace pressure and continued process optimization.

Improvements in substrate handling are required to reduce yield loss due to glass breakage and to meet the demands of the faster processing rate required to achieve a 10 Megawatt throughput. Crucial substrate handling steps include loading and unloading of the a-Si:H deposition system. When entering the system, a large piece of glass must be rotated from a horizontal to a vertical position, positioned precisely into a transport fixture and latched into place and then repeated in reverse order when exiting the system. This complicated task must be accomplished by automated (robotic) equipment in a precise manner at a high repetition rate. Design experience gained from the construction of an automated loader/unloader for the smaller $1^{\prime} \times 1^{\prime}$ manufacturing line at Solarex will be used to guide the development of this new equipment for larger substrates at a faster throughput rate.

In the present manufacturing process, many steps involve rotation of the module by $90^{\circ}$, flipping the module from horizontal to vertical as it transfers the module between high vacuum and ambient (atmospheric) environments through a load lock. These steps take time, add expense and complexity to the equipment. Some of the improvements planned for the new line include elimination of many of these "non-value added" process 
steps. This may require laser patterning in a vertical, rather than horizontal position, and possibly even performing the laser scribing in a vacuum eliminating the need to break vacuum or to pass through a load lock. In some instances, handling steps can be eliminated simply by better lay-out of the process line.

Automation of the" back-end" steps is planned for the advanced line. These "back-end" steps currently entail mechanical abrasion of the encapsulation polymer over the electrical contact pads, cutting, stripping, assembly and manual soldering of the electrical output cables and packaging of the finished module. Methods presently under consideration involve automated abrasion and soldering, or possibly pre-encapsulation masking of the contact pad areas, followed by automated "solder reflow" bonding using "thermodes" of metal tab connectors. The elimination of much of the manual labor required for these steps will greatly reduce the labor cost for module manufacture.

Because of the larger scribing distances, the movement and control of the beam positioning optics becomes more complicated. Besides this requirement for $x-y$ accuracy in beam positioning, the larger substrate span will require active $z$-axis control to maintain adequate beam focus. Preliminary work to utilize automatic substrate distance sensing to accomplish z-axis focus control has begun at Solarex.

\section{(ii) Yield Loss Considerations}

Yield loss represents a real cost that must be included in the price of the finished product. Yield loss can be a significant component in a process sequence where the individual steps exhibit only "fair" yields. Reduction of yield loss during processing will accomplished by 1) controlling the formation of microscopic debris during the CTO deposition, 2) minimizing temperature variations of the module during processing, 3) improved substrate handling to avoid mechanical glass breakage and 4) development of an improved shunt "curing" technique.

The improvements in design of the a-Si:H deposition chambers for temperature uniformity and the improved substrate handling by automated equipment with minimal rotation of the substrate are expected to reduce substrate breakage. Similarly, the special design of the large CVD belt furnace used for CTO deposition is also intended to solve the CTO debris 
problem. This factor has been correlated with yield loss due to electrical failure of modules caused by excessive shunting of individual segments. The origin of these shunts are believed to be point defects that cause conductive paths between the top and bottom collecting contacts of the cell. A growing body of evidence indicates that this shunting problem can be minimized by careful control of the CTO and a-Si:H deposition processes and by minimizing the temperature variation and time spent between a-Si:H deposition and metallization. The time between a-Si:H deposition and metallization is the time during which any removal or flaking of microscopic debris from under the thin film semiconductor results in a pinhole which becomes a shunt defect upon metallization. In today's second generation production line, the module is metallized immediately after a-Si:H deposition. The a-Si:H scribe that would normally be done between these two steps is replaced with a "double direct" laser scribing process performed after all of the layers have been deposited. Although the double direct method is used with success today for the manufacture of single junction modules, it has not been thoroughly evaluated in terms of its effect on triple junction modules.

The effective curing of shunt defects is another area that requires development. Several improvements to the present method of curing electrical shunts have been proposed, including one new method for finding and permanently removing the shunt defect. This new method uses the same laser technology used for laser scribing and would entail a process for both locating and scribing out the defects responsible for the largest shunts.

\section{(iii) Material Usage and Cost}

The cost model was able to identify the various cost components associated with each proposed change in cell design. By calculating the projected usage of materials, utilities and capital equipment required for each proposed process in the sequence, it was easy to identify new opportunities for cost reduction. Large improvements in the cost/watt are projected based on the use of high efficiency, stable triple junction devices and from the scale-up to larger size and volume. In addition, the model indicated that further cost reductions were possible by 1) improved gas utilization for deposition of the semiconductor layers and 2) material substitution in the rear contact. 
The most costly constituents of the triple junction cell (excluding the frame) are the silane and the germane gases used for deposition of the a-Si:H based semiconductor layers. Cost modelling indicated that the consumption of these relatively expensive hydrides could be substantially reduced by increased hydrogen dilution. This has now been experimentally confirmed in the laboratory, with hydrogen dilution leading to improved semiconductor material properties. Thus, based on actual data from the present Solarex manufacturing line, improved gas utilization can be attained via hydrogen dilution. In addition, experience gained through the design of two earlier generations of deposition systems, will be used to improve the design of the electrodes and gas distribution equipment to further improve gas utilization.

Solarex Thin Film Division has also developed and demonstrated the technology for feed gas reclamation and recycling via cryogenic gas condensation in the exhaust stream. Calculations indicate that this approach could be applied to recover, at a good recovery efficiency, the germane gas used in the triple junction technology. Presently, about $90 \%$ of the silane gas in the exhaust stream can be recovered by this method. The estimated recovery rate of germane is approximately $78 \%$. The economic value of gas reclamation will depend on the effectiveness of the improvements in gas utilization described above. If the measures to improve gas utilization are extremely successful, there may be too low a concentration of either silane or germane in the exhaust stream to economically extract them.

The cost model identified the rear contact materials as the next most costly cell constituent after framing and semiconductor materials costs. There is also a good opportunity to reduce the cost of this component by substitution of less expensive materials. In the laboratory, the triple junction cells have a rear contact of indium tin oxide, followed by metallic silver. The cost of the metallic silver is high because silver sputtering targets are typically made of high purity metals and carry a high fabrication charge. This same problem in the single junction process was eliminated for the sputtered aluminum targets through the use of much less costly industrial purity aluminum and the development of sputtering equipment that largely eliminates the target fabrication charge. These same innovations, when applied to the triple junction cell design, can significantly reduce the materials cost of the silver in the PV module. 
The cost of the indium tin oxide in the rear contact is also significant. This may be reduced by the substitution of zinc oxide. The use of zinc oxide in place of the indium tin oxide has been recently demonstrated in the laboratory at Solarex.

\section{(iv) Transfer of Triple Junction Technology to Manufacturing}

The DOE sponsored research effort at Solarex Thin Film Division has resulted in the capability to produce $1000 \mathrm{~cm}^{2}$ triple junction modules in the laboratory on a routine basis with beginning of life efficiencies between 9 and 10\%.7 Measurements indicate that these modules have a stabilized (one year) efficiencies of approximately $8 \%$. The transfer of this technology from research to manufacturing will provide a crucial improvement in the price/performance ratio for amorphous silicon based PV modules. The ability to produce these high conversion efficiencies on $1000 \mathrm{~cm}^{2}$ modules in research at Solarex, greatly reduces the risk and simplifies the effort required to transfer this technology into a manufacturing process.

The triple junction development effort at Solarex is in its early stages. Further gains in efficiency and stability are expected to result from continued research efforts. Stabilized efficiency of $12 \%$ is one of the goals of the current SERI/DOE supported research program at Solarex Thin Film. Present research centers around 1) improving the semiconductor material quality via hydrogen dilution and optimizing the deposition conditions, 2) better device design through bandgap modification and grading, 3) improving the front and rear contacts and 4) improving the overall module design. None of these areas involve increased expenses in terms of materials or processes over the present triple junction process technology used as the basis of the cost model.

\section{(v) Framing}

From the cost modelling it is readily apparent that the frame is by far the largest component of cost for an a-Si:H based PV module. This is clearly a generic issue for all of PV. In many instances, the frame serves as mechanical support for the module, as an environmental seal for the module edge and as a means of mounting the module for use. However, an a-Si:H based module is completely functional on a stand-alone basis 
without a frame. For this product, the requisite mechanical strength and environmental protection are inherent in the bare encapsulated "plate", namely the unframed module. Thus for applications where aesthetics are not important and large quantities of modules are required, such as utility scale applications, it should be a simple task to eliminate the frame altogether. Using these frameless modules will require the development of robust, convenient and inexpensive means of mounting unframed modules.

\section{(vi) Encapsulation and Accelerated Testing}

Environmental protection of the PV module from mechanical and chemical damage as well as isolation of the electric circuit is a generic issue for all PV modules. For thin film modules, corrosion is one of the most common methods of field failure. Study of this problem at Solarex Thin Film Division has identified many problems involving module encapsulation and lead to solutions that provide for long term durability of Solarex's thin film PV modules. However, much remains to be done to extend the environmental durability of thin film modules even further, and to develop better means of accelerated testing of alternative encapsulation and module designs. In particular, reliable means of accelerated environmental testing that correctly simulates extended outdoor exposure, will be required if thin film PV modules are to satisfy the needs of potential large scale users. 


\section{REFERENCES}

1. R.G. Chamberlain, "Product Pricing In The Solar Array Manufacturing Industry-An Executive Summary of SAMICS", Thirteenth IEEE Photovoltaic Specialist Conference, p. 904,1978.

2. B. Jackson, J. Glyman, P. McGuire, P. Henry, H. Awaya, D. Burger and S. Herman, "Advanced Photovoltaic Module Costing Manual", SERI/TR-214-1965, 1983.

3. J.H. Wohlgemuth, S.P. Shea, R.K. Brenneman and A.M. Ricaud, "Elimination of Edge Roll-Off In Cast Semicrystalline Silicon", Nineteenth IEEE Photovoltaic Specialist Conference, p. 1524, 1987:

4. J.H. Wohlgemuth, "Casting Polycrystalline Silicon for Photovoltaics", Proceedings of International Symposium-Workshop on Silicon Technology Development and Its Role in the Sun-Belt Countries, 14-18 June 1987, Islamabad, p. G-1.

5. J.H. Wohlgemuth, S. Narayanan and R. Brenneman, "Cost Effectiveness of High Efficiency Cell Process as Applied to Cast Polycrystalline Silicon", Twenty First IEEE Photovoltaic Specialist Conference, p. 221, 1990.

6. J.H. Wohlgemuth and R.C. Petersen, "Solarex Experience with Ethylene Vinyl Acetate Encapsulation", Solar Cells, In Press.

7. A.W. Catalano, "Advances in a-Si:H Alloys for High Efficiency Devices", Twenty First IEEE Photovoltaic Specialist Conference, p. 36, 1990.

8. A.W. Catalano, Technical Digest of the PVSEC-5, Kyoto, Japan, p. $235,1990$.

9. M. S. Bennett, A.W. Catalano, K. Rajan and R.R. Arya, "Improved Stability in Amorphous Silicon Germanium Solar Cells Made From Hydrogen-Diluted Silane and Germane", Twenty First IEEE Photovoltaic Specialist Conference, p. 1653, 1990. 
10. J. H. Wohlgemuth and S. Narayanan, "Impact of Defects on the Perfromance of Silicon Solar Cells Made on Cast Polycrystalline Silicon", SERI Workshop on the Role of Point Defects/Defect Complexes In Silicon Device Fabrication", August 30-31, 1990.

11. S. Narayanan, J. Zolper, F. Yan. S.R. Wenham, A.B. Sproul, C.M. Chang and M.A. Green, "18\% Efficient Polycrystalline Silicon Solar Cells", Twenty First IEEE Photovoltaic Specialist Conference, p. 678, 1990.

12. B.L. Sopori, "Influence of Oxygen on the Performance of Silicon Solar Cells", Twentieth IEEE Photovoltaic Specialist Conference, p. 591, 1988.

13. C. Hauser, "Latest Results and Expected Possibilities of Wire Wafering Technology", Proceeding of the Ninth E.C. PV Solar Energy Conference, p. 437, 1989. 


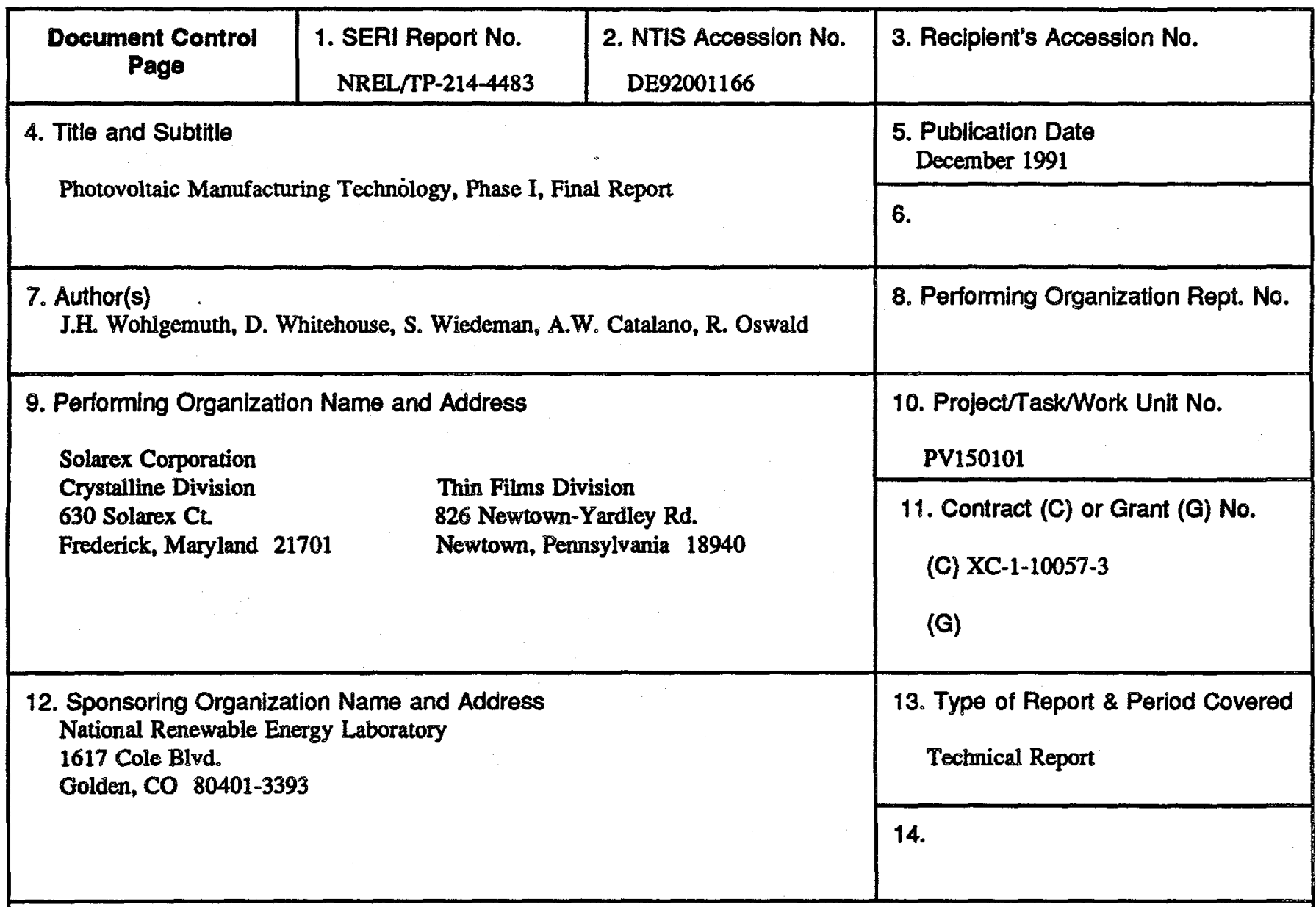

15. Supplementary Notes

NREL technical monitor: R. Mitchell

16. Abstract (Limit: 200 words)

This report identifies steps leading to manufacturing large volumes of low-cost, large-area photovoltaic (PV) modules. Both crystalline silicon and amorphous silicon technologies were studied. Cost reductions for each step were estimated and compared to Solarex Corporation's manufacturing costs. A cost model, a simple version of the SAMICS methodology developed by the Jet Propulsion Laboratory (JPL), projected PV selling prices. Actual costs of materials, labor, product yield, etc., were used in the cost model. The JPL cost model compared potential ways of lowering costs. Solarex identified the most difficult technical challenges that, if overcome, would reduce costs. Preliminary research plans were developed to solve the technical problems.

\section{Document Analysis}

\section{a. Descriptors}

photovoltaic manufacturing ; amorphous silicon ; solar cells ; crystalline silicon ; silicon wafers ; low-cost manufacturing ; photovoltaics ; cost analysis

\section{b. Identifiers/Open-Ended Terms}

\section{c. UC Categories 270}

18. Availability Statement National Technical Information Service U.S. Department of Commerce 5285 Port Royal Road Springfield, VA 22161
19. No. of Pages 48

20. Price

A03

Form No. 0069E (6-30-87) 